\title{
A memória outsider em A figueira do inferno do Telephone Colorido
}

\author{
Ricardo César Maia'
}

1. Possui graduação em Comunicação Social com habilitação em Jornalismo (2005.2) pela Universidade Católica de Pernambuco - Unicap e Mestrado em Comunicação / Estética e Cultura Midática (2009.2) pela Universidade Federal de Pernambuco - UFPE, com orientação de Paulo Cunha. Atualmente é doutorando em Comunicação / Mídia e Estética também pela UFPE, com orientação de Nina Velasco e Cruz, e professor da Aeso - Faculdades Integradas Barros Melo. E-mail: rmaiaj80@gmail.com 


\section{Resumo}

Este artigo pretende investigar o audiovisual pernambucano: A figueira do inferno (2004) do coletivo Telephone Colorido. Sobretudo, a partir do que esse material pode problematizar enquanto produto de uma memória outsider. E é através de um olhar fílmico não-convencional entre conceitos e realizações audiovisuais mediadores da memória que busca-se entender as transformações do cinema e da própria sociedade brasileira contemporâneos, em tensão analítica e embates críticos.

\section{Palavras-Chave}

Memória, outsider, audiovisual.

\section{Abstract}

This article investigates the audiovisual from Pernambuco-Brazil: A Figueira do Inferno (2004), made by the collective Telephone Colorido. Especially from what this material can discuss as a product of a memory outsider. And it is through a look unconventional filmic between concepts and achievements audiovisual mediators of memory that seeks to understand the transformations of cinema and contemporary brazilian society, in tension analytical and clashes critical.

\section{Keywords}

Memory, outsider, audiovisual. 


\section{Conceitos e aproximações teóricas}

Aparentemente, essa relação entre a memória, o outsider e o audiovisual do coletivo pernambucano Telephone Colorido, A figueira do inferno (2004), pode soar distante ou mesmo absurda. Mas, é através dessa tríade que vão ser inferidos os pontos em tensão da análise! Para fins metodológicos, optei, primeiramente, por desenvolver um panorama teórico a respeito da aproximação entre a memória e o outsider, em seguida, vou contextualizar o processo criativo do filme e, concomitantemente, colocar os três elementos da pesquisa juntos, de fato, para debater e ir afunilando as linhas de encontros e de conflitos.

A memória nos ajuda a recordar e a nos atualizar, mas, paradoxalmente, escapa, engana, ilude, nos passa pra trás! E nesse jogo de autenticidade entre o real e a virtualidade, além da memória, a percepção e a afecção, o espírito e o corpo lutam, geralmente, por uma racionalidade de comportamento que se transparece na ação do indivíduo perante os outros. Pois, estamos sempre no processo de ser vigiados e punidos e também de estar vigiando e punindo! E a repressão ao comportamento desviante pode dar-ser, de modo geral, devido a condutas indevidas em lugares ou situações inapropriadas, porém essas concepções variam de pessoa para pessoa, de grupo para grupo e de cultura para cultura - para não esquecer que estamos falando de relações, de trocas entre o indivíduo e o coletivo.

Comumente, pensa-se a memória como uma referência direta ao passado, uma tentativa de resgatar uma lembrança qualquer, ou seja, o simples ato de lembrar, recordar, etc. Por isso, é importante perceber que além da memória nostálgica ou melancólica ou saudosista, há uma memória de vontade política, de atuação na malha social e no desenvolvimento individual. O que fica escondida com essa definição primeira é a força de transformação da memória, que o segundo conceito aborda. A partir desse embate, duas questões aparecem: primeiro, como atua essa memória instigada? Através do confronto entre o que fica no ostracismo da coletividade e aquilo que foi posto como o fato ou a coisa que vai ser lembrado, que vai representar ou reverberar no espírito coletivo. E essa tendência política da representação é essencial para pensar a memória outsider, 
pois segundo a concepção de José Van Dijck sobre a cultural memory sempre há "um ato de negociação ou luta para definir a individualidade e a coletividade 2 (DIJCK, 2007, p. 12. Tradução minha). A memória cultural é interessante para perceber que há uma relação e, consequentemente, um confronto entre essa dualidade! E é a partir desse conflito que aparece a necessidade de trazer à tona temas, coisas e fatos a fim de termos um debate social mais amplo, seja sobre alguma questão marginalizada ou a respeito de um produto ilegal, como é o caso do filme do Telephone Colorido.

O segundo questionamento é: há uma memória ligada ao passado e outra ao porvir? Essa questão é importante para tirarmos a carga linear e temporal da memória, dessa forma, reforçando o embate que envolve o recurso de memorização! Pois, a distinção cronológica do tempo não compreende o dinamismo da memória como processo em constante mudança, pois é no movimento não-linear que essa relação se dá e no calor do momento presente. Então, a memória resulta na mistura entre o passado, o presente e o futuro, entre a afecção e a percepção, enfim, entre o corpo e o espírito, todos percebidos enquanto unidades conceituais, mas, principalmente, entendidos como parte de um sistema maior, que está sempre aberto ao infinito.

O que é, para mim, o momento presente? É próprio do tempo decorrer; o tempo já decorrido é o passado, e chamamos presente o instante em que ele decorre. Mas não se trata aqui de um instante matemático. Certamente há um presente ideal, puramente concebido, limite indivisível que separaria o passado do futuro. Mas o presente real, concreto, vivido, aquele a que me refiro quando falo de minha percepção presente, este ocupa necessariamente uma duração. Onde portanto se situa essa duração? Estará aquém, estará além do ponto matemático que determino idealmente quando penso no instante presente? Evidentemente está aquém e além ao mesmo tempo, e o que chamo "meu presente" estende-se ao mesmo tempo sobre meu passado e sobre meu futuro [...] É preciso portanto que o estado psicológico que chamo "meu presente" seja ao mesmo tempo uma percepção do passado

2. "an act of negotiation or struggle to define individuality and collectivity". 
imediato e uma determinação do futuro imediato. Ora, o passado imediato, enquanto percebido, é, como veremos, sensação, já que toda sensação traduz uma sucessão muito longa de estímulos elementares; e o futuro imediato, enquanto determinando-se, é ação ou movimento. Meu presente portanto é sensação e movimento ao mesmo tempo; e, já que meu presente forma um todo indiviso, esse movimento deve estar ligado a essa sensação, deve prolongá-la em ação. Donde concluo que meu presente consiste num sistema combinado de sensações em movimentos. Meu presente é, por essência, sensório-motor (BERGSON, 1999, p. 161-162)

Esse conceito bergsoniano ajuda a responder o segundo questionamento lançado na análise, pois é incontestável que o fundo de intuição real, e por assim dizer instantâneo ou presente, sobre o qual se desenvolve nossa percepção do mundo exterior através do corpo é fortemente envolvido com tudo o que nossa memória nele acrescenta - estando ela nesta movimentação das sensações do passado com a ação futura. E quando aliado à memória instigada e ao embate entre memória e outsider é possível perceber que há sempre um confronto, seja no processo de construção do intelecto através da percepção temporal, seja no atrito ou no limite dos corpos, seja na troca de ideias. Em meio ao embate temporal também acontece o embate político entre o coletivo e o indivíduo por uma memória cultural, e é daí que emergem as memórias mediadas pelas tecnologias da mídia! O produto audiovisual é um desses objetos mediadores da memória:

Memórias mediadas são as atividades e os objetos que nós produzimos e nos apropriamos por meio das tecnologias de mídia, para assim criar e recriar um senso de passado, presente e futuro de nós mesmo em relação aos outros. Objetos e atos mediadores de memória são cruciais para a negociação entre o que conta como privado e como público, e como a individualidade se relaciona com a coletividade. Como momentos tranquilos no passado e no futuro - lembrando e projetando experiência vivida. Memórias mediadas não são objetos estáticos ou depósitos, mas relações dinâmicas [...] Memórias mediadas referem-se tanto aos atos de memória (interpretando uma identidade relacional gravada em dimensões de tempo) e produtos de memória (objetos pessoais de memória onde as mentes individuais e o coletivo se encontram). 
O termo não é nem um deslocamento da definição psicológica de pessoal da memória cultural, nem é um desligamento da noção de coletivo da memória cultural do historiador. Em vez disso, ele oferece uma ferramenta para analisar casos complexos de formação e transformação da memória, tendo a caixa de sapato com itens pessoais como objeto culturalmente relevante ${ }^{3}$. (DIJCK, 2007, p. 21-22)

Essa tomada de posição em favor da memória cultural sendo ela a tensão entre o indivíduo, o coletivo e os produtos midiáticos, salienta mais ainda a faceta política da memória - a fim de que os agentes da esfera privada saiam do ostracismo e acrescentem algo ao reino público, levantando questões relevantes sobre a identidade do indivíduo numa cultura específica e em certo momento da contemporaneidade. Através desse entendimento sobre o importante papel das mídias na construção da memória cultural de uma pessoa, de um grupo e de uma sociedade, é necessário discorrer sobre dois pontos no intuito de saber o que queremos colocar a respeito disso: primeiro, que essa noção de memória mediada não se restringe aos meios massivos de comunicação, como a televisão e o rádio, ela compreende muito mais esses produtos privados, como objetos íntimos de uma coleção pessoal de lembranças e produções outsiders; e é a partir daí que o segundo ponto se apresenta, pois é com essa necessidade de dar voz à caixa de sapatos com itens pessoais mediadores e das realizações midiáticas desviantes que a memória marginalizada pretende romper com os eixos de ação do discurso convencional ou hegemônico de construção da memória cultural - seja ela do indivíduo ou coletiva ou mesmo que esteja no entrelugar dessa relação.

3. Mediated memories are the activities and objects we produce and appropriate by means of media technologies, for creating and re-creating a sense of past, present, and future of ourselves in relation to others. Mediated memory objects and acts are crucial sites for negotiating between self and culture at large, between what counts as private and what as public, and how individuality relates to collectivity. As stilled moments in the past and future - remembering and projecting lived experience. Mediated memories are not static objects or repositories but dynamic relationships [...] Mediated memories refers both to acts of memory (construing a relational identity etched in dimensions of time) and to memory products (personal memory objects sites where individual minds and collective meet). The term is neither a displacement of psychological definition of (personal) cultural memory, nor it is a dislodgment of the historian's notion of (collective) cultural memory. Instead, it offers a tool for analyzing complex cases of memory formation and transformation, taking personal shoebox items as culturally relevant objects. 
É por essa razão que a memória outsider se aproxima mais à idealização da memória individual, pois ela acaba sendo restrita a um pequeno grupo de pessoas. Porém, mesmo tendo uma pequena repercussão, é uma memória cultural também,

de fato e por direito! Com essa memória desviante, o embate entre as memórias individual e a coletiva é constante, talvez, com mais fervor pela forte tendência política de sair do ostracismo. Assim como os relatos dos indivíduos comuns vêm revolucionando a história tradicional com sua narrativa calcada em grandes feitos e nomes, a memória marginalizada das mídias audiovisuais também é o caminho para expansão da pesquisa científica, seja ela cinematográfica ou sociológica ou psicológica ou em qualquer outro campo de estudo afim. E para compreender melhor e ampliar o que anseio denominar enquanto memória outsider, a visão sociológica de Howard S. Becker sobre comportamento desviante é fundamental:

[...] grupos sociais criam desvio ao fazer as regras cuja infração constitui desvio, e ao aplicar essas regras a pessoas particulares e rotulá-las como outsiders. Desse ponto de vista, o desvio não é uma qualidade do ato que a pessoa comete, mas uma consequência da aplicação por outros de regras e sanções a um "infrator". O desviante é alguém a quem esse rótulo foi aplicado com sucesso; o comportamento desviante é aquele que as pessoas rotulam como tal. (BECKER, 2008, p. 22)

É importante pensar sobre a memória porque ela molda o comportamento, a moral, a ética e todo o aparato a mais que compõe o agente cultural na malha da sociedade. Então, essa memória mediada outsider não é somente aquela que escapa ou que nos ilude, ela é, principalmente, aquela que incomoda, que infringe uma regra, que tem um comportamento desviante, que enfrenta os tabus. Por isso, talvez, seja aquele tipo de lembrança que a maioria das pessoas faz questão de esconder ou mesmo esquecer! Elas podem ser também aquela memória traumática ou neurótica! Todavia, ela também pode ser aquela memória política, revolucionária, de ruptura, do limite, da transgressão! E é através dessa luta pela memória cultural que os produtos outsiders são importantes na construção crítica e a criativa do indivíduo e da coletividade, por um movimento de expandir as identidades e de não cristalizar as relações com os outros. 
Não há razão para se supor que somente aqueles que finalmente cometem um ato desviante têm impulso de fazê-lo. É muito mais provável que a maioria das pessoas experimente impulsos desviantes com frequência. Pelo menos em fantasia, as pessoas são muito mais desviantes do que parecem. Em vez de perguntar por que desviantes querem fazer coisas reprovadas, seria melhor que perguntássemos por que as pessoas convencionais não se deixam levar pelos impulsos desviantes que têm. (BECKER, 2008, p. 37)

Esses impulsos desviantes povoam e incitam a memória do sujeito para atuar na coletividade munido de produtos midiáticos. E a resposta para a pessoa fugir da tentação do ato desviante pode ser encontrada "no processo de compromisso pelo qual a pessoa 'normal' torna-se progressivamente envolvida em instituições e comportamento convencionais" (BECKER, 2008, p. 37). E é assim que há o controle do impulso desviante, pois o sujeito acaba pensando nas múltiplas consequências que podem ser acarretadas por ceder à essas memórias outsiders. Os itens da memória desviante mediados - também denominados como Memory's tecnologization: “a memória é também central para a construção de um senso de continuidade entre o indivíduo e o outros"4 (DIJCK, 2007, p. 3, tradução minha) - são importantes ferramentas conceituais, pois lançam outras perspectivas e associações inusitadas à análise cultural, o que expande as subjetividades nas tensões entre o poder e o saber, numa perspectiva estética e, consequentemente, política e poética dos audiovisuais.

E é valendo-se da noção da dinâmica dos micropoderes e da aproximação com produtos fílmicos obscuros e pouco debatidos, que o embate crítico pretende trazer inferências sobre os esquemas dos habitus e as estruturas dos $\operatorname{campos}^{5}$ da coletividade e do indivíduo, em tensão.

Além de reconhecer que o desvio é criado pelas reações de pessoas a tipos particulares de comportamento, pela rotulação desse comportamento como

\footnotetext{
4. "memory is also central to constructing a sense of continuity between our selves and others".
}

5. [...] há, de um lado, uma gênese social dos esquemas de percepção, pensamento e ação que são constitutivos do que chamo de habitus e, de outro, das estruturas sociais, em particular do que chamo de campos (BOURDIEU, 1990, p. 149) 
desviante, devemos também ter em mente que as regras criadas e mantidas por essa rotulação não são universalmente aceitas. Ao contrário, constituem objeto de conflito e divergência, parte do processo político da sociedade. (BECKER, 2008, p. 30)

Os produtos audiovisuais outsiders fazem parte desta memória desviante que nos escapa. Eles tocam em temas tabus e assuntos interditados que as instituições estabelecidas e os comportamentos convencionais tentam deixar esquecidos ou imperceptíveis, com o intuito de que ninguém referencie nem debata a respeito. Talvez, seja por isso que esses produtos da transgressão acabem sendo atemporais! O conteúdo e a forma fílmicos permanecem sendo contemporâneos, no sentido de Giorgio Agamben (2009), pois esses produtos audiovisuais ainda carregam relevância e pugência enquanto elementos de transformação cultural. E através dessa aproximação conceitual com o contemporâneo de Agamben, várias indagações surgem, como: o que acontece a uma obra ou a um artista para ser ou não ser contemporâneos? Deixar de ser outsider seria a razão decisiva, pois passaria a ser estabelecido? Algumas dessas produções podem ser apontadas em uma condição de eterna transgressão? O contemporâneo é o outsider?

Para Agamben, o contemporâneo procura nas sombras, a eminência de uma luz que não se encontra, de fato, mas que impulsiona a movimentação do pensamento crítico/criativo: "reconhecer nas trevas do presente a luz que, sem nunca poder nos alcançar, está perenemente em viagem até nós" (AGAMBEN, 2009, p. 66). Ele seria, na verdade, um inatual, um desconectado, e é nesse anacronismo que, paradoxalmente, o agente pertence mais ao seu tempo, não no sentido cronológico temporal, daqueles que se deixam cegar pelas luzes de sua época, pois "aqueles que coincidem muito plenamente com a época, que em todos os aspectos a esta aderem perfeitamente, não são contemporâneos porque, exatamente por isso, não conseguem vê-la, não podem manter fixo olhar sobre elas" (AGAMBEN, 2009, p. 59); o contemporâneo está na direção daqueles que expandem os limites das coisas procurando na escuridão, a origem, num eterno retorno renovado: "a contemporaneidade tem o seu fundamento nessa proximidade com a origem que em nenhum ponto pulsa com mais força do que no presente" (AGAMBEN, 2009, p. 69). 
Entre o arcaico e o moderno está a chave do contemporâneo, pois ele busca coisas escondidas no imemorial e no pré-histórico. Não é um movimento de simples regressão nostálgica “a um passado remoto, mas a tudo aquilo que no presente não podemos em nenhum caso viver e, restando não vivido, é incessantemente relançado para a origem, sem jamais poder alcançá-la" (AGAMBEN, 2009, p. 70). Por isso que ser contemporâneo significa, paradoxalmente, "voltar a um presente em que jamais estivemos" (AGAMBEN, 2009, p. 70), no sentido de garimpar e, consequentemente, lançar novas possibilidades para o instante-já, através dessa movimentação temporal, pois “todos os tempos são, para quem deles experimenta comtemporaneidade, obscuros" (AGAMBEN, 2009, p. 62-63).

[...] não se pode falar em retorno às condições perdidas na história, mas que somente nos é possível entrever em meio às luzes do presente o escuro que lhe é inerente, uma origem que não está fora da história, mas que garante um olhar não saudosista para o passado e um mirar o futuro sem esperanças outras que não a própria capacidade de repensar o presente. (AGAMBEN, 2009, p. 21-22)

O que nos leva a pensar a história como esse processo contínuo de rememoração em que o passado retorna, não como fato, mas como abertura e imprevisibilidade. Nesse sentido, a memória desviante estaria na escuridão das mentes dos seres humanos, para aqueles que não a procuram, provavelmente, ela deve estar instalada no inconsciente ou mesmo rejeitada por uma consciência doutrinada pelas condutas e pelas instituições convencionais estabelecidas.

Os comportamentos e os produtos outsiders não atuam por uma transgressão sem sentido, esvaziada de intenções políticas. Ao contrário, eles estão impregnados de conflitos, de rupturas, de descontinuidades, de dissensos, de revoluções, enfim, de transformações na memória cultural do indivíduo e da coletividade. E é nesse embate conceitual, estético e político que o discurso fílmico d'A figueira do inferno do grupo pernambucano Telephone Colorido pode nos apresentar um relevante confronto teórico entre o audiovisual e a associação lançada pela pesquisa através da concepção da memória outsider. 


\section{A figueira do inferno}

O filme é um documentário de curta-metragem (25'13' '), lançado em 2004. Nos letreiros iniciais do audiovisual, a obra é apresentada assim: Telephone Colorido \& Rec Produtores Associados apresentam: A figueira do inferno: um registro etnobotânico da utilização de Daturas e Brugmânsias no Nordeste brasileiro. E no final do filme, as funções são destacadas: realização do Telephone Colorido e coprodução da Rec Protudores Associados, ou seja, os membros do TC que dirigiram, roteirizaram, editaram a imagem e o som, enfim, eles que conceberam, de fato, a feitura audiovisual da obra e os integrantes da Rec fizeram a produção executiva ou burocrática. O roteiro de Abel Alencar, Ernesto Teodósio e Raoni Valle foi premiado pelo concurso Ary Severo e Firmo Neto realizado pelo governo do estado de Pernambuco e pela prefeitura da cidade do Recife, isto é, teve incentivo do Funcultura do Governo de Pernambuco através da secretaria de Educação e Cultura e da Prefeitura do Recife. Um filme de baixo orçamento com uma equipe de trabalho mínima de 23 pessoas elencadas nos letreiros finais de créditos, entre, direção, roteiro, edição, produção, design, equipe de fotografia e de som, os motoristas, psiconautas e consultores em etnobotânica e um etnomusicológico, além de laboratório, estúdio de mixagem e telecines de $16 \mathrm{~mm}$ e super 8 . Enfim, essa descrição da produção é interessante para perceber que não é independente no sentido de os realizadores arcarem os custos da produção dos próprios bolsos e também pode parecer uma proposta atrelada a interesses alheios, pelo fato do roteiro ter sido adequado a uma seleção a partir de editais de instituições públicas. Mas aí que está o engano, pois, ao mesmo tempo, A figueira do inferno não deixa de ser uma produção independente, outsider. A realização funciona como armadilha, pois fez entrar em ação o poder público a serviço das lutas contra a violência simbólica. Conseguiu tirar proveito da condição do patrocínio e fazer um produto legitimado por instituições estabelecidas que analisa um tema interditado, parar ser mais específico, a questão das drogas, da ilegalidade e uso marginal de algumas substâncias!

E, dessa maneira, concebendo um produto audiovisual enquanto memória mediada desviante o qual luta para expandir a subjetividade dos comportamentos convencionais e dos discursos doutrinados, que o Telephone Colorido dá voz 
a uma memória outsider, que toca indiretamente na origem das ocupações humanas no Brasil. Em depoimentos de índios, de caboclos, de pajés, de paisde-santo, de mães-de-santo, de curandeiros, de cientistas e de usuários comuns, a análise documental aborda os usos de Daturas e Brugmânsias no Nordeste brasileiro - plantas nativas que foram associadas às drogas psicoativas, mas que também carregam benefícios na feitura de medicamentos e usos terapêuticos. $\mathrm{O}$ antropólogo etnobotânico, Pedro Luz, fala em som direto um texto introdutório que sintetiza bem o argumento fílmico:

\footnotetext{
Este documentário que veremos mapeia o uso contemporâneo de espécies no gênero Brugmânsia e Datura no Nordeste brasileiro. Tal é devedor do uso de três matrizes culturais: o xamanismo ameríndio, o curandeirismo africano e o complexo de medicina folk. E bruxaria luso-brasileira que aqui forjaram uma tradição difusa do uso destas plantas! Tradição essa que revela as virtudes terapêuticas das mesmas, como plantas medicinais. E seu uso mais co-ritual decorrente de suas propriedades psicoativas, cada vez mais deturpáveis e descontextualizadas.
}

O grupo fez um longo percurso para realizar as entrevistas do documentário, a ordem e as cidades percorridas são essas: Recife, Caruaru, Condado, Baía da Traição, Icapuí, Fortaleza, Almofala, Jericoacoara, Tatajuba e Camocim. Três municípios em Pernambuco, um na Paraíba e seis no Ceará. Muitos dos dados apresentados até agora já nos apontam algumas possíveis relações com a memória outsider. Há um movimento de ressignificação de um contexto do passado nativo que podemos relacionar com a origem brasileira. $\mathrm{O}$ foco do documentário é uma planta que se tornou maldita devido ao seu uso psicoativo, o que fez com que ela fosse enquadrada numa condição desviante, reprimindo o seu uso tóxico e, consequentemente, seu uso medicinal; apesar de que a transformação do material bruto em remédio formatado, ou seja, em produto farmacêutico, faz com que as pessoas ignorem o fato de estarem utilizando substâncias proibidas. O caminho feito pelo Telephone Colorido para colher os depoimentos também revela geograficamente e historicamente uma região tida como o berço da nação, mas esquecida pelos interesses políticos e econômicos, 
o que a torna desconhecida para o grupo dominante ou hegemônico do país. E por fim, outro aspecto do documentário é a mistura dos status dos entrevistados na tentativa de mesclar os conhecimentos e de legitimar discursos outsiders em meio a posições estabelecidas.

Os nomes mais comuns dessas plantas - assim como nos revela o diálogo entre o Dr. Raiz e Seu Biu no Mercado de Ervas de Caruaru quando eles consultam a página exata do livro "A flora nacional na medicina doméstica" - são: figueira-do-inferno, dente-de-leão, guerreiro-do-mar, mamoninho-bravo, trombeta, zabumba, jabumba, aubaitinga-dos-índios, erva-dos-mágicos, ervados-feitiçeiros, erva-do-diabo, erva-dos-demoníacos, pomo-espinhoso, pomo-dodiabo. E o valor terapêutico: as folhas e sementes frescas trituradas e cozidas em azeite têm aplicação em irritações contra as dores reumáticas; usa-se também a erva seca em cataplasma e fomentações. Os dois - Dr. Raiz e Seu Biu - comentam sobre a quantidade de usos que podem se fazer com essas plantas, mas por elas serem tóxicas, eles alertam que devem ser usadas para problemas externos, não para os problemas internos; enfim, para aplicar sobre a pele e não para ingerir. E quando falam sobre tomar o chá, advertem que pode causar a morte ou profundas perturbações mentais! Com esses depoimentos já é possível perceber as primeiras interdições que esse vegetal carrega, além da associação religiosa com o demônio e ao mal que algumas nomenclaturas representam, ainda há o risco da morte ou de sequelas no sistema nervoso e, por fim, a recomendação ao uso controlado e específico, assim podemos fazer uma dupla leitura: da cautela por ser uma substância tóxica e da proibição por seu uso poder acarretar em condutas desviantes e indesejadas.

E a partir dessa apresentação inicial dos vegetais pela perspectiva do conhecimento popular dos dois representantes dos saberes não legitimadas pelas ciências, o filme segue nos mostrando as vozes dessas pessoas que acabam ficando de fora desse debate institucionalizado pelas universidades, pelos grupos de pesquisas e pelas empresas de remédios. Mais uma vez é perceptível a política dos poderosos que acaba selecionando os grupos hegemônicos e silenciando vozes desviantes com regras de imposição do saber. Então, seguimos viagem e encontramos Zé Borba em Condado-PE! Apesar de Dr. Raiz e Seu Biu não 
recomendarem e não relatarem sobre a utilização interna dessas plantas, como eles mesmos disseram, outros entrevistados pelos documentaristas vão falando como se deve tomar e preparar para o consumo, assim como Zé Borba. Ele também não tem diplomas universitários, mas vai explicando quais devem ser os preparativos para o uso do chá: "três dias sem tomar nada de álcool, sem tocar na mulher. Tem que chegar simples, como você nasceu". E canta uma reza que deve ser feita antes de botar a planta na água: "flores da terra que planta tu desse, me aproximo de ti, pra tirar uma flor de ti, para a cura me dar". Zé Borba diz que é cientista, porque consegue perceber as plantas e dizer se aquele vegetal serve para tal remédio: "eu falo com as plantas e elas me dizem". E vai falando da filiação pessoal para justificar o conhecimento: “minha vó era cabocla de mata, nunca tomou remédio. Eu sou filho de umbanda, sou pai-desanto, porque índio é índio".

Depois, vamos para Baía da Traição na Paraíba onde o Telephone Colorido entrevista Maria Grossa e Seu Domingos da tribo Potiguara. Ela explica o que se pode fazer para consumir a planta por via oral, mas faz uma ressalva de que não pode ser muita a quantidade da planta e recomenda: "só três folhinhas, das pequenas. Pra uma criança, só é uma! É bom pra tosse". Seu Domingos fala do uso para cortes, para impinge. Mostra como manipula a planta cortando-a em dois para botar aberta na ferida. Diz que o efeito pode ser ruim ou bom e que banhos espirituais também são realizados com esses vegetais.

Esses três depoimentos fazem o conhecimento popular caminhar das referências da sabedoria dos mercados públicos para os procedimentos domésticos dos mestiços e dos índios! O audiovisual vai se transformando através de seu conteúdo no resgate de um passado distante, marginalizado, mas também, paradoxalmente, tão próximo. E nesse movimento de repaginação, as lembranças outsiders se ligam com o esforço político do ser contemporâneo em redefinir limites e propor outras possíveis ligações históricas para a memória cultural; que a ultrapasse, que a expanda!

E isso implica uma atualização, uma organização da memória e dos eventos que inventam um mundo, uma pessoa, inexistente até então! Estando entre indivíduos que dão a ver as possibilidades de criação que os ultrapassa, o outro 
ano 2 número 3

Dossiê

se propaga no audiovisual, o outro se inventa com o filme e com a memória. Pois, o “interesse do documentário está em sustentar o 'entre atualizações', a individuação, a virtualidade, aquilo que ainda não pertence a x ou a y, mas que vibra e está a ponto de se atualizar" (MIGLIORIN, 2010, p. 16). Aproveitando o gancho deixado por Cezar Migliorin, é preciso contextualizar o documentário-objeto da discussão em termos da linguagem da produção audiovisual contemporânea!

Nas últimas décadas, o campo do documentário passou por mudanças estrondosas! Segundo Francisco Elinaldo Teixeira, as principais transformações se deram, principalmente, pelo advento da cultura cibernético-informacional e com a voracidade do digital, que permitiu o uso e reuso de vários elementos audiovisuais, realizando combinatórias do antigo com o novo, do próximo com o distante, do documentário com a ficção, dessa maneira, colocando os materiais em novos ciclos. Outro diferencial do documentário contemporâneo é o grande deslocamento operado na cadeia produtiva: em vez de produção, é a esfera da pós-produção que se converte no momento privilegiado. E por fim, outra característica importante é, após décadas tentando inscrever o "outro" - exótico ou distante, próximo ou familiar -, após realizar uma varredura que englobou os mais diversos temas e assuntos, o documentário volta a câmera para trazer o universo pessoal do realizador. Inicia-se uma busca sem fim das próprias origens, da tentativa de dar uma inscrição a esse "eu”, de fazê-lo condição, base ou propósito da enunciação documentária. É aí que a memória outsider ganha espaço, na contemporaneidade das realizações audiovisuais, pois, a caixa de sapatos repleta de objetos pessoais e de produtos midiáticos, que se tornaram uma das principais fontes dos objetos mediadores da memória, possui um vasto repertório de temas interditados.

Enfim, o lugar de destaque que o documentário foi adquirindo na última década costuma levantar a indagação: a que se deve tamanho relevo na cultura audiovisual? Quase invariavelmente a resposta imediata é: trazer de volta a realidade para uma cultura que a transformou em resíduo mediante processos de virtualização. O reality show, o docudrama e outras formas de realismo sociocultural é perpassada inteiramente pelos dados de uma 
realidade que não para de se duplicar cotidianamente e cuja saturação nos atinge por todos os lados. Nesse sentido, ao contrário desse senso comum por mais-realidade, padecemos de um excesso diante do qual, felizmente, podemos contra com a arte do documentário para evitar que nos mate a realidade. Desse modo, pode-se dizer que o documentário contemporâneo, se por um lado constrói uma linha de fuga do excesso de realidade que nos invade, por outro, volta-se na direção de um "real" que nos escapa e desafia em sua inextricável exterioridade. Daí a frequente sensação de confusão, de indiscernibilidade entre o documental e o ficcional de que somos hoje tomados. (TEIXEIRA, 2006, p. 285)

O documentário do Telephone Colorido apresenta algumas características comuns ao audiovisual contemporâneo, mas diverge em relação a outras elencadas, acima. Não faz uso de uma pós-produção elaborada, não seria o estágio mais importante da cadeia produtiva. Apesar disso, insere-se no mundo digital através do sentido da hibridização dos materiais fílmicos e das combinações desencanadas de tendências artísticas e, nesse contexto de saturação da realidade através de estímulos audiovisuais, nos apresenta um "real" que nos escapa e desafia. Também não parte para uma realização pessoal, mas carrega uma característica em comum com esse tipo de feitura fílmica, que é estar numa condição à margem das grandes narrativas históricas e a partir daí ter enfrentamentos na perspectiva da micro-política. A figueira do inferno é um outro exótico, mas é um ser do reino vegetal! E o enfoque do discurso fílmico é sobre a proibição e o uso clandestino e nativo das plantas. Porém, o documentário não é um grito que finda na nulidade da demanda audiovisual; é sim um mundo singular na sua diferença, sem isolamento! As interdições feitas por conta das leis de entorpecentes decretam a morte de uma planta, pois ela fica enquadrada como ilegal, o que invibializa os diversos usos que esses vegetais possuem, muitas vezes medicinais. Além da proibição para fins psicoativos, o que revela a seleção social sobre quais substâncias podem ser consumidas com essa finalidade.

Os procedimentos de uso sejam pela ingestão ou pela epiderme revelam, além da utilização prática da planta, as pronúncias do português feitas por pessoas com baixos graus de escolaridade e as manipulações rústicas do material bruto, 
ano 2 número 3

Dossiê

o que não significa uma falta de conhecimento, na verdade, aponta para outra realidade de um grupo distinto do cidadão brasileiro urbano. Entre universidades, pequenas cidades, vilas e tribos indígenas no sertão e no litoral nordestino, o Telephone Colorido vai desmistificando os entraves que envolvem esses vegetais através do conhecimento popular e científico! Voltando para o bloco que tenta explicar como a figueira do inferno pode ser utilizada, essa parte do filme é finalizada com as declarações do professor José Matos da Universidade Federal do Ceará e de Manoel Pitaguari, em Maracanaú-CE. O primeiro relata que a planta é extremamente útil como espasmolítica, que oftalmologistas usam em colírios para dilatar a pupila e que ela também é utilizada para medicamentos que combatem as cólicas, como o Buscopan. Mas, alerta também que essa mesma planta, em dosagens altas, pode causar danos cerebrais irreversíveis! Manoel Pitaguari diz que tanto serve para humanos quanto para animais, dizendo que é utilizada para matar carrapato em carneiros e cachorros e piolho em pessoas! O que fica mais do que evidente com esses relatos, são os benefícios agregados ao uso da trombeta, todavia também é clara a ressalva feita em relação ao uso tóxico, seja como veneno ou para efeitos psicoativos. E a partir desse ponto da análise fílmica, uma questão surge: o que as coisas, as pessoas e as memórias rotuladas de desviantes têm em comum? "No mínimo, elas partilham o rótulo e a experiência de serem rotuladas como desviantes" (BECKER, 2008, p. 22). Por carregar o rótulo e a experiência de ser outsider, A figueira do inferno tem o status de planta maldita, associada ao diabo e a coisas culturalmente ruins. E esse produto mediador da memória cultural criado pelo Telephone Colorido através do audiovisual quer mostrar à sociedade um tema e discursos escamoteados e vai através dessa premissa desvendando práticas desviantes.

É preciso deixar claro também que a memória outsider acontece no encontro entre as mídias e a memória, pois “desde as ferramentas da escrita, porém de forma mais notável a partir da emergência da fotografia no século XIX, a capacidade humana cotidiana para lembrar tem sido ordenada pelas ferramentas técnicas para reprodução"6 (DIJCK, 2007, p.17, tradução nossa). A relação é

6. "of writing tools, but most noticeably since the emergence of photography in the nineteenth century, the human capacity to remember has been indexed in daily language by referring to technical tools for reproduction". 
de construção mútua e é a partir desse entrave de poder na memória cultural partilhada que muitos produtos mediadores de lembranças ficam fora de plano, o que faz surgir a categoria dos outsiders, que está ligada a materiais domésticos e produções transgressoras. Dessa maneira, quem está nesta última posição carrega potências de transformação cultural que são de suma importância para a contemporaneidade! A grande questão é saber se as pessoas estão preparadas ou interessadas por repaginações! E é através da política que a memória desviante pode propor novos pactos sociais, com o intuito de oxigenar a malha cultural, seja com rupturas ou com resgates de ideias e de ações pertinentes.

Saindo da investigação sobre os possíveis usos e a origem da figueira do inferno, os realizadores nos apresentam um grupo de usuários que utilizaram a planta para conseguir efeitos alucinógenos. São eles: Pêu e Carlos da Baía da Traição e, Seu Nô e Zé Carlos de Icapuí-CE. Vou sintetizar o que eles relataram sobre, para depois seguir analisando! Pêu diz que só tomou uma vez e, segundo ele, a dosagem estava muito forte e deu errado! Ele teve alucinações e passou três dias sob efeito da planta. Pêu afirma que se sente uma pessoa diferente depois daquela experiência e por isso não se considera uma pessoa normal. E finaliza dizendo que é a droga mais forte que existe! Seu Nô afirma que a planta é mais forte do que o crack, do que a cocaína, enfim, do que qualquer outra droga psicoativa. Conta que a pessoa fica sem noção das ações e pode se machucar que não vai sentir dor nenhuma até que os efeitos alucinógenos passem. Carlos, expondo duas plantas na mão, explica que ele e seus amigos tomavam o chá porque não tinham opção nem dinheiro para usar outras drogas e também porque queriam ficar extremamente "chapados". Já Zé Carlos mostra a figueira do inferno plantada no chão e daí começa a falar que a pessoa pode tomar atitudes inesperadas, como bater na mulher e ofender a mãe: "prejudica teu coração e teu cérebro pra andar à toa em ilusão". Em seguida, há um corte e estamos dentro de uma casa, talvez a do próprio Zé Carlos, onde ele está preparando o chá de trombeta numa panela com água e limão. Começa a tocar a música de Raul Seixas e Paulo Coelho, de forma não diegética: "Eu nasci há dez mil anos atrás", o que ajuda a endossar o uso milenar dessa planta pelos povos nativos do Brasil. Ele diz que o líquido tem que ficar vermelho e que eles estão se 
ano 2 número 3

Dossiê

preparando para fazer um estudo sobre a Zabumba com o pessoal do Telephone Colorido. A equipe da produção fílmica começa a fazer parte da cena!

Esse é o bloco temático sobre os usuários da planta para fins psicoativos. Os grupos e indivíduos assumem condutas desviantes e vão nos trazendo à tona uma memória aparatada pelo dispositivo audiovisual que aborda, ao mesmo tempo, os hábitos dos primeiros povos que viveram nas terras brasileiras, a ingestão atualizada pelos nativos e por pessoas dos grandes centros urbanos e também um uso que é tratado como impróprio, como ilegal, pois estamos falando de uma droga alucinógena, tema tratado como proibido pelas leis federais. Por essas razões que é importante perceber as variáveis desta memória desviante, pois o que pode ser outsider para um grupo pode não ser para outro - isso pode acontecer vivendo num mesmo país ou região, como acontece nesses casos mostrados no documentário. É preciso também esclarecer que essas posições não são estanques, mas que estão vivas em constante relação e movimento. Aquilo que pode ser encarado como execrável para uns, pode ser utilizado por outros para fins legitimados e de benefícios comuns. Mas, os juízes oficiais acabam considerando tudo num mesmo saco homogêneo de condutas desviantes e o perigo dessas repulsas generalizadas é a falta de detalhes e de aprofundamento sobre os comportamentos desviantes, que acabam sendo enquadrados em perfis simplificados e grosseiros de estatísticas ou de linhas teóricas deterministas. E é dando vozes às memórias outsiders e aos diferentes discursos sobre uma temática interditada, que o Telephone Colorido vai desmistificando o uso da figueira do inferno, num tom de documentário investigativo.

Em seguida, somos levados para um sobrevôo sobre o território indígena Tremembé em Almofala-CE, lá a equipe do audiovisual encontra mais um uso diferente para a planta. O pajé Tremembé, Luiz Caboco e Dona Tarciza Tremembé falam que a folha pode ser seca e usada para fumar, eles afirmam que faz bem para cansaços no peito. O pajé Luiz Caboco conta um relato importante para entender mais sobre as utilidades, os perigos da dosagem exagerada e as restrições do uso da trombeta: "essa planta foi muito proibida por isso que acabou. Ela toda serve de remédio. Usamos aqui mais a flor e a folha. É boa pra puxada velha do peito, mas ao mesmo tempo ela tem um processo. Ela envenena". Luiz Caboco 
faz questão de ressaltar a proibição da planta e, em seguida, fala dos benefícios e malefícios do uso da trombeta. O que é importante notar nesse depoimento é a existência de lugares e grupos que resistem às interdições impostas pelos poderes hegemônicos, fazendo com que a memória outsider permaneça viva, mesmo que seja de forma restrita ou marginalizada.

E de Almofala-CE vamos para Jericoacoara, também no Ceará, onde assistimos aos depoimentos de nativos e de pessoas provenientes da capital cearense sobre o consumo de zabumba por lá, o que atraiu muitos turistas por conta dos efeitos alucinógenos da planta, desde o ano de 1977, segundo o relato de Yuri de Fortaleza. Dona Geralda fala de um menino de oito anos que comeu a zabumba e morreu. Diz que ele ingeriu de manhã e faleceu à tarde. Ela conta que o pessoal de fora da cidade fazia o chá do zabumba pra ficar "doido". Yuri relata que a comunidade de Jericoacoara toda sabia sobre o uso do chá da zabumba, que era uma coisa coletiva e que depois virou caso policial. Para ele, a trombeta é uma droga, de fato, e não deixa de endossar os riscos do consumo: "o maxixe é completamente sem controle. É muito forte, não recomendo. Já bebi a planta inteira. É forte demais". É interessante perceber que depois que os riscos do uso são sentidos por Yuri e que a zabumba torna-se ilegal, ele vai mudando de opinião sobre a proibição da planta. A pressão social e as más experiências individuais vão alterando os seus argumentos!

O professor José Mato tenta sintetizar o espírito do uso da trombeta, a partir de 1968 com o lançamento do livro de Carlos Castañeda: "depois do livro da Castañeda, A Erva do Diabo, muitas pessoas fazem uso em suas reuniões, em brincadeiras e farras".

A erva-do-diabo tem quatro cabeças: a raiz, a haste e as folhas, as flores, e as sementes. Cada qual é diferente, e quem a tornar sua aliada tem de aprender a respeito delas nessa ordem. A cabeça mais importante está nas raízes. O poder da erva-do-diabo é conquistado por meio de suas raízes. A haste e as folhas são a cabeça que cura as moléstias; usada direito, essa cabeça é uma dádiva para a humanidade. A terceira cabeça fica nas flores e é usada para tornar as pessoas malucas ou para fazê-las obedientes, ou para matá-las. O homem que tem a erva por aliada nunca absorve as flores, nem 
mesmo a haste e as folhas, a não ser no caso de ele mesmo estar doente; mas as raízes e as sementes são sempre absorvidas; especialmente as sementes, que são a quarta cabeça da erva-do-diabo e a mais poderosa das quatro.

Jericoacoara por ser uma praia com atributos geográficos convidativos para o turismo e, além disso, ainda teve algo a mais que foi o uso do chá de zabumba, assim, a cidade acabou tornando-se uma zona de comportamentos desviantes por conta da planta. Por isso, existe um passado outsider impregnado na memória cultural do lugar e das pessoas que ainda moram e que conviveram por lá. Depois que o rótulo desviante de droga tomou conta da planta, os comportamentos vão sendo empurrados para uma perspectiva impregnada de desvio e da consequente interdição do uso, das condutas acarretadas pelo consumo e dos discursos sobre.

Arlindo Artur de Jericoacoara comenta sobre um velho que andava nu pelas ruas da cidade - segundo ele, "virando bicho" e tendo alucinação - por conta do chá de zabumba. Mas, ele contextualiza dizendo que esse uso é novo e que veio depois do turismo. E Baíca relata um caso de uma moça paulista que tomou o chá de zabumba: “entrou na sala do forró, nua, saiu rebolando. Um rapaz amarrou-a e depois, veio um pessoal de São Paulo para pegá-la de avião e levá-la para casa".

Para finalizar essa sequência de relatos sobre o consumo do chá de trombeta por turistas, Delmira de Nova Tatajiba-CE conta a história de um rapaz que perceptivelmente era de fora da cidade e que vinha andando em círculos ao redor da residência dela. Ele parou na frente da casa de Delmira, porque avistou uns pés de figueira do inferno e daí foi pedir a ela pra fazer um chá da flor de zabumba, alegando que estava gripado, com a dor de cabeça e que aquele chá ia melhorar a doença dele. Então, sem saber a real finalidade do uso do chá pretendido pelo rapaz, ela preparou o líquido bem concentrado, deu para ele beber e com dez minutos, o rapaz fechou os olhos. Começou a roncar e a sair baba da boca dele! Delmira correu percebendo que aquilo poderia dar em alguma tragédia e fez uma garapa com bastante açúcar pra ele tomar. O rapaz foi melhorando e depois acordou. Por fim, ela disse para o rapaz que ele ia morrer envenenado e 
reclamou por ele ter pedido para fazer o chá com a zabumba, pois ela não sabia o que acontecia nem como proceder com o chá da planta. Esses relatos são interessantes para perceber que o uso da figueira do inferno é ampliado para um contexto de uma cidade, Jericoacoara, e também para um turismo narcótico, assim como acontece com Amsterdã.

O filme é todo calcado em entrevistas na tentativa de mostrar uma pluralidade de olhares sobre o tema. Entre o roteiro e o improviso, os encontros acabam se colocando sob o risco do real. É possível perceber através da montagem que existem blocos temáticos por grupos de entrevistados, mas o filme aqui não é apenas uma sequência audiovisual que tem uma determinada duração, pois o que está em jogo são as indeterminações, o descontrole e o improvável, ou seja, a potência do acontecimento, irredutível à programação de um roteiro que servirá simplesmente para o consumo. Ele é feito, na verdade, para que o espectador seja transportado para a instabilidade dos encontros entre sujeitos políticos.

Muitos dos mais relevantes filmes recentes, como sabemos foram fundados nessa disposição para o encontro. Acompanhamos nos últimos anos uma série de dispositivos, entrevistas e invenções de situações em que não havia uma roteirização possível, em que o documentário se colocava sob "risco do real", como escreveu Comolli. Esse risco permitia marcar a diferença e a contraposição entre cena e roteiro. Oposição construída por Comolli para que possamos pensar a partir da presença ou não de um operador externo. Ou seja, a cena é o lugar da negociação das representações em que os sujeitos operam, enquanto o roteiro aparece como uma operação exterior à tensões da cena, colocando o espectador não como um eventual personagem ativo da cena, mas como um consumidor do quadro acabado. No roteiro, o sujeito encontra seu papel já desenhado, sabe como deve atuar para que a ordem narrativa funcione, enquanto a cena é política. (MIGLIORIN, 2010, p. 14)

As tensões e os tabus da memória outsider vão sendo revelados a partir dos encontros em que os agentes se colocam sob o risco da real. Essa é a tônica d' A figueira do inferno! No filme, é possível notar que uma pré-produção bem elaborada mapeou a maioria das pessoas selecionadas para as entrevistas, mas 
as falas não seguem um roteiro fechado de perguntas, elas ganham corpo com as tensões que a temática propicia ao discurso e também com a forma que os membros da equipe de filmagem tratam os entrevistados. O Telephone Colorido empreende um documentário em que o dissenso é a ordem narrativa e, assim, os indivíduos enfrentam politicamente a coletividade. Tentando mudar a pauta da memória cultural, o audiovisual mexe nos buracos mais profundos e nos cantos mais distantes da recordação brasileira sobre a origem dos primeiros nativos.

O filme encaminha-se para o seu final com os depoimentos dos dois cientistas que são entrevistados durante o documentário, o professor José Matos da UFC e o antropólogo etnobotânico, Pedro Luz, além das falas deles, o audiovisual intercala essas cenas com outras dos três integrantes da equipe da filmagem tomando o chá da Datura e da Brugmânsia - a primeira estava sendo feita, como relatei anteriormente, por Zé Carlos de Icapuí, e a segunda foi preparada pelo próprio Pedro Luz. Os membros do Telephone Colorido que tomam as substâncias são denominados nos créditos do audiovisual como psiconautas: Jonatas Ferreira, Ananías Caldas e Raoni Valle. Sobre as reações dos três, a primeira experiência com a Datura é relatada por Zé Carlos, não há registro audiovisual no filme, além da fala do entrevistado. Ele diz que os rapazes ficaram a noite toda sem dormir, reclamando de formigas na pele e querendo, à noite, entrar no mar para pescar, mas o próprio Zé Carlos impediu isso por recear afogamentos. A segunda experiência também não é documentada no audiovisual nem relatada, o filme acaba com os três, além do próprio antropólogo, tomando o chá da Brugmânsia.

Os últimos relatos dos dois intelectuais são importantes para o fechamento da produção. José Matos fala sobre os possíveis sintomas para quem usar o chá da zabumba, como: pele seca, temperatura alta, pupila dilatada. E comenta sobre uma substância que pode ser usada como efeito contrário à trombeta caso a pessoa esteja passando mal, que é a policarpina encontrada no jaborandi: “se não conseguir o chá, corre para a farmácia mais próxima pra comprar um colírio de policarpina pro camarada beber". Dessa maneira, ele prossegue e apresenta uma alternativa inusitada para o uso da planta enquanto alucinógeno por pessoas interessadas: "daí, você vê a necessidade de ter alguém que possa orientar as pessoas que têm facilidade de acesso aos tóxicos, de ter alguém que 
possa orientá-los na hora da intoxicação". E quando questionado sobre o porquê dessas plantas terem esses efeitos tóxicos, ele tenta explicar: "uma teoria é que isso é o lixo do metabolismo, outros dizem que é uma evolução muito elaborada pra evitar o ataque de animais herbívoros".

Por fim, a fala de Pedro Luz vai introduzindo o ritual de preparo e da ingestão do chá. É interessante ler na íntegra a decupagem feita diretamente do audiovisual, pois ela finaliza o documentário em tom de poesia e profético:

\begin{abstract}
Colhendo as flores da espécie Brugmânsia. Sendo cozinhadas para o experimento psiconáutico. Nos preparando para o encontro com essa planta. É uma planta muito disciplinadora, a disciplina dela é muito grande e muito forte. A gente sabe que tem tribos indígenas que administram o uso dessa planta para crianças rebeldes. Se a gente respeita a disciplina dela e sabe, se aproxima com confiança, com coragem e com empenho, ela pode nos abençoar e nos apresentar seu espírito de uma forma prazerosa, para que nós possamos ganhar conhecimento com essa planta e com o corpo espiritual também. Três dedos de copo pra cada um da equipe de filmagem. (A figueira do inferno, 2004)
\end{abstract}

Essa sequência final com os depoimentos dos saberes legimitados pela ciência e também com a ingestão das substâncias pelos integrantes do Telephone Colorido é uma maneira de tirar a carga desviante das plantas. Pois, faz uso do poder discursivo dos cientistas para desmistificar o uso do chá para fins psicoativos, ora falando sobre uma possível orientação de um especialista para evitar danos ou mortes ora compartilhando com os membros da equipe de filmagem a substância alucinógena; essas são ações e ideias impróprias para a ciência atrelada a instituições estabelecidas. E a exibição audiovisual do uso, apesar de se limitar a mostrar só o ato da ingestão e não os efeitos posteriores, também fortalece a intenção política de mostrar ao público que o status desviante da Datura e da Brugmânsia é um tabu ou um mito social criado para impedir a liberdade da utilização ampla das plantas por pessoas interessadas.

É importante perceber que o que guia o filme são os vegetais e é a partir deles que os seres humanos são apresentados no audiovisual criado pelo Telephone 
ano 2 número 3

Dossiê

Colorido. Do acontecimento à sua rarefação e, de novo, à possibilidade do acontecimento, os selecionados para formar o discurso fílmico d'A figueira do inferno vão compondo uma gama de abstrações mescladas entre o visível, o sonoro, o sensível e o conceitual; tudo em torno das plantas proibidas. Cercando essa memória outsider e, dessa maneira, possibilitando uma experiência não apenas audiovisual, mas política, o filme nos possibilita encontros sob o risco do real onde nada é naturalizado ao ponto de ser uma verdade única sobre esse tema; o que ele nos propicia é cercar o assunto através das possibilidades audiovisuais realizadas pelo Telephone Colorido.

Essa espécie de "atenção desatenta" é o que permite o encontro - o afeto

- entre o olho e o mundo: encontro distendido pelo tempo, mediado pela câmera, transfigurado pela edição digital (parcimoniosa aqui). Não há, contudo, a ilusão de que basta olhar o mundo para que ele se revele aos nossos olhos: objetivo e transparente. Nada é puro, natural. Apesar de seu aparente naturalismo, estas são paisagens eletrônicas, acontecimentos mediados, mundos que só podem emergir entre: o evento e sua dissolução em pixels. A paisagem eletrônica, que se produz entre o artifício e a natureza, é ainda uma paisagem temporal. Nela, a duração possui uma dimensão estética, mas também política. (BRASIL, 2010, p. 174-175)

\section{Considerações finais}

A crítica inferencial levantada pela tensão analítica entre a memória, o conceito sobre o outsider e o filme A figueira do inferno do Telephone Colorido apontou para uma relação instável, porém bastante frutífera e intrigante. O audiovisual enquanto produtor de uma memória mediada desviante não ousa na forma fílmica, é o conteúdo em si que rememora uma temática escamoteada, interditada pelas regras impostas pelas condutas "normais" dos grupos e das instituições convencionais. Permanecer na condição outsider não é uma questão de ganhar público e visibilidade, de jeito nenhum, mas sim um posicionamento político perante o tempo presente, e é com essa postura que o contemporâneo continua em seu movimento pela escuridão, na busca de ressignificações culturais. $\mathrm{O}$ filme mostra um panorama de variáveis que compõe a visão dos usuários, dos 
especialistas populares e dos cientistas com o intuito de direcionar essa memória desviante para uma condição mais favorável perante as restrições de uso e do conhecimento. Talvez, a única perspectiva que faltaria ao produto audiovisual seja a opinião dos inquisidores, dos juízes, para assim termos uma compreensão mais ampla ainda. Todavia, a proposta do Telephone Colorido cumpre sua função de elucidar um debate desmistificador a respeito desta memória outsider, garimpada pelo grupo em, A figueira do inferno. E ter conseguido financiamento através das instituições públicas, que geralmente não estão interessadas em discutir temas polêmicas, também é um aspecto relevante na trajetória fílmica da obra, pois endossa a capacidade de manobra política do coletivo. 


\section{Referências}

AGAMBEN, Giorgio. O que é o contemporâneo? E outros ensaios. 1ª edição. Chapecó: Editora Argos, 2009.

BECKER, Howard Saul. Outsiders: estudos de sociologia do desvio. $1^{\text {a }}$ edição. Rio de Janeiro: Editora Jorge Zahar, 2008.

BERGSON, Henri. Matéria e memória: Ensaio da relação do corpo com o espírito. $2^{\mathrm{a}}$ edição. São Paulo: Editora Martins Fontes, 1999.

BOURDIEU, Pierre. Coisas Ditas. 1ª edição. São Paulo: Editora Brasiliense, 1990.

BRASIL, André. Ensaios de uma imagem só In: MIGLIORIN, Cezar (org.). Ensaios no real. Rio de Janeiro: Editora Beco do Azougue, 2010.

CASTAÑEDA, Carlos. A erva do diabo. Rio de Janeiro: Editora Nova Era, 2009.

MIGLIORIN, Cezar. Documentário recente brasileiro e a política das imagens In: MIGLIORIN, Cezar (org.). Ensaios no real. Rio de Janeiro: Editora Beco do Azougue, 2010.

TEIXEIRA, Francisco Elinaldo. Documentário Moderno In: MASCARELLO, Fernando (org.). História do Cinema Mundial. Campinas: Editora Papirus, 2006.

VAN DIJCK, José. Mediated memories in the digital age: Cultural memory in the present. $1^{\text {a }}$ edição. California: Stanford University Press, 2007.

\section{Referências Filmográficas}

A figueira do inferno, um registro etnobotânico da utilização de Daturas e Brugmânsias no Nordeste brasileiro. Direção: Raoni Valle e Ernesto Teodósio (Telephone Colorido). 2004. Colorido. Recife-PE. Cor/som. 16 mm, 8 mm e digital. 25 min - http://www.youtube.com/watch?$\mathrm{v}=\mathrm{tdNgGm-zkQc.} \mathrm{Acesso} \mathrm{em:} 13$ de maio de 2013. 